\title{
Avaliação Emancipadora: Educação de Jovens e Adultos e Educação Profissional
}

\author{
Emancipatory Evaluation of young and adult education with \\ the Vocational Education
}

\author{
Erlando da Silva RÊSES ${ }^{1}$ \\ Reinouds Lima SILVA²
}

\begin{abstract}
Resumo
O presente artigo avalia o Programa de Educaçáo de Jovens e Adultos integrada à Educação Profissional (PROEJA) no Instituto Federal do Maranhão - Campus Açailândia. Fez-se uso da metodologia da avaliaçáo emancipadora: descrição da realidade, crítica da realidade e criação coletiva (SAUL, 2006). O levantamento de dados foi por meio de grupos focais com discentes, docentes e técnico-administrativos e discussão por Análise de Conteúdo (BARDIN, 2011). A descriçáo da realidade compreendeu dados da localidade, planos de curso e Programa. Na crítica da realidade prevaleceu a percepção dos sujeitos e na criação coletiva enfatizaram-se as contradiçóes e as proposiçóes.
\end{abstract}

Palavras-chave: Avaliação de Política Pública. Educação de Jovens e Adultos. Educação Profissional.
Abstract

This current paper assesses the PROEJA - Brazilian Program of Young and Adult Education integrated to the Vocational Education - in the Federal Institute of Maranhao - Campus Acailandia. The emancipatory evaluation methodology was applied: reality description, reality criticism and collective creation (Saul, 2006). The survey of data was carried out by means of focus groups with students, teachers and technicians through Content Analysis (Bardin, 2011). The reality description involved locality data, course plans and Program. The individuals' perception predominated in the reality criticism and the contradictions and proposals were emphasized in the collective creation.

Keywords: Assessment of Public Policy. Young and Adult Education. Vocational Education.

1 Doutor em Sociologia pela Universidade de Brasília (UnB). Líder do Grupo de Estudos e Pesquisas sobre Materialismo Histórico-Dialético e Educação (CONSCIÊNCIA) da FE/UnB. Membro do Grupo de Estudos e Pesquisas sobre o Trabalho (GEPT) do Departamento de Sociologia da UnB. Professor da Faculdade de Educação (FE) e do Programa de Pós-Graduação em Educação da FE/UnB. Campus Universitário Darcy Ribeiro - Asa Norte, Brasília, DF. CEP 70910-900. Tel.: (61) 3107 6265. Email: <erlando@unb.br>.

2 Mestre e Doutorando em Educação pelo Programa de Pós-Graduação em Educação da Universidade de Brasília. Faz parte do Grupo Estudos e Pesquisa em Materialismo Histórico-Dialético e Educação (CONSCIÊNCIA) da FE/UnB. Professor de História do Instituto Federal do Maranhão. Rodovia MA201 - Km 12, Bairro Piçarreira - São José de Ribamar, MA. CEP 65110-000. Tel.: (98) 3215-1701. Email: <reinouds.silva@ifma.edu.br>.

R. Educ. Públ.

Cuiabá

v. 27

n. $65 / 1$

p. $425-446$

maio/ago. 2018 


\section{Introdução}

Este estudo buscou avaliar o Programa Nacional de Integração da Educação Profissional com a Educação Básica na Modalidade de Educação de Jovens e Adultos (PROEJA), instituído pelo Decreto n. ${ }^{\circ}$ 5.478/2005 (BRASIL, 2005) e revisado pelo Decreto n. ${ }^{\circ}$ 5.840/2006 (BRASIL, 2006), e especialmente foi analisada a implantação do PROEJA no Instituto Federal do Maranhão (IFMA), Campus Açailândia. A pesquisa se desenvolveu no período de março de 2013 a fevereiro de 2015.

A avaliação de políticas e programas educacionais envolve um amplo espectro de variáveis, que em relaçáo ao pretendido pelo Estado como formulador e indutor da política, notadamente, envolve elementos que podem não ter sido contemplados, considerando a política pós-implantação e em execução. $\mathrm{O}$ modelo referencial que acreditamos ser possível nesse processo de investigação e em sua posterior avaliaçáo encontra aporte na Avaliação Emancipadora proposta pela pesquisadora Ana Maria Saul. Como referencial em avaliação, a proposta da autora promove a inserção dos vários atores do processo efetivo da execução e realidade institucional em que a política educacional se desenvolve, propondo "[...] uma análise valorativa do programa educacional na perspectiva de cada um dos participantes (avaliadores) que atuam” (SAUL, 2006, p. 62).

Para tanto, fez-se uso da entrevista coletiva com aplicação da metodologia de avaliação emancipadora, que aborda a participação coletiva, compreendendo três momentos específicos: descrição da realidade, crítica da realidade e criação coletiva, concebendo que todos os momentos se desenvolveram na fase da pesquisa de campo, em especial com a realização de entrevista em grupo, por segmentos específicos da comunidade escolar. Essa segmentação se justifica pela necessidade de promover, especialmente com os alunos, a possibilidade de exprimir suas críticas e sugestôes de modo livre, minimizando a sobreposição de perspectivas específicas entre os segmentos. A comunidade escolar do IFMA - Campus Açailândia compóe-se dos segmentos discente, docente e técnico administrativo.

Os discentes que participaram das entrevistas em grupo compunham os matriculados regularmente do primeiro ao terceiro ano no curso técnico em meio ambiente integrado ao ensino médio na modalidade EJA (PROEJA), no ano letivo de 2014. Trata-se de grupo heterogêneo, com variação de idade entre 18 e 67 anos. Predomina o perfil de estudantes trabalhadores, incluídas nessa categoria as donas de casa. O segmento discente participou de três sessôes de entrevistas em grupo, divididos os momentos por turmas específicas do primeiro ao terceiro ano de curso, perfazendo um total de 38 participantes, ou seja, $48,1 \%$ do total de alunos matriculados.

O grupo dos servidores da instituição foi segmentado entre professores e técnicos administrativos. Todos são servidores efetivos, tendo em média até três 
anos de efetivo exercício. Os professores têm atuação no PROEJA considerando o curso atualmente ofertado em relação às suas áreas de formação e de concurso público. Os técnicos administrativos, por ocuparem cargos nos setores de apoio ao educando, têm envolvimento direto com o Programa avaliado. As entrevistas em grupo foram realizadas nos dois segmentos, sendo cinco docentes e três técnicos, perfazendo $35,1 \%$ e $50 \%$ respectivamente, do total de servidores.

$\mathrm{Na}$ pesquisa qualitativa, a utilizaçáo das entrevistas em grupo tem como funçáo "[...] fornecer dados para testar expectativas e hipóteses desenvolvidas fora de uma perspectiva teórica específica [...]" e "[...] desempenhar um papel vital com a combinação de outros métodos" (BAUER; GASKELL, 2002, p. 65), e assim encontrar na possível contradição entre os documentos oficias e as inferências dos entrevistados a superação da aparência homogênea do processo social e educacional e a efetividade da política pública em análise. $\mathrm{Na}$ realização de entrevistas foi necessário mobilizar os participantes para que as críticas expressas, especialmente subsidiando as observações e inferências do pesquisador, fossem acompanhadas da possibilidade de suas superaçóes com proposições que surgissem da própria comunidade.

O corpus de dados recebeu tratamento específico a partir da análise de conteúdo proposta por Bardin (2011), que, por análise categorial e específica por segmento e em cada etapa da avaliação emancipadora, ofereceu os dados necessários para qualitativamente proceder às interpretaçóes.

Dentre as possibilidades de uso da análise de conteúdo, a estruturação dos dados por categorização se mostrou conveniente. Para Bardin (2011, p. 149), "[...] a categorização tem como primeiro objetivo (da mesma maneira que na análise documental) fornecer, por condensação, uma representação simplificada dos dados brutos." A autora prossegue, afirmando que "[...] a análise de conteúdo assenta implicitamente na crença que a categorização [...] não introduz desvios (por excesso ou por recusa) no material" (BARDIN, 2011, p. 149).

Seguindo a metodologia proposta, os dados foram organizados em recortes e inseridos por quadros de análise, separados por categorias determinadas, de modo a favorecer não apenas as inferências, mas também aproximar-se das etapas previstas na metodologia de avaliação. As categorias determinadas para organização dos dados foram:

a. Formação Profissional no IFMA - Campus Açailândia;

b. Currículo Integrado no PROEJA;

c. Acesso e permanência;

d. Condiçóes de ensino e aprendizagem;

e. Expectativas e possibilidades. 
De posse dos dados para uma análise qualitativa, foi possível obter as condiçôes necessárias para empreender também avaliação da política educacional, com todos os atores da pesquisa assumindo também o papel de indutores de processo avaliativo com os envolvidos na pesquisa, condição mais que necessária na avaliação proposta por este estudo.

Registramos que esta pesquisa se soma a outros estudos sobre o PROEJA e sua articulação com as instituiçóes federais de educação profissional. Tais pesquisas e suas abordagens conferem importância a esse tema, bem como demonstram o esforço em compreender melhor a realidade da educaçáo profissional. Este estudo e seus resultados se somam ao conjunto de estudos e autores no esforço de superação da realidade da educação de jovens e adultos como política pública na cena educacional brasileira.

\section{Sobre a Rede Federal de Educação Profissional}

A expansão da rede federal de educação profissional e tecnológica, iniciada em 2006 pelo governo federal, ampliou os pontos de presença do Instituto Federal do Maranháo de apenas quatro unidades para 29 até o momento, com projeção de chegar a 33 até meados do ano de 2019.

Trata-se de processo expansionista da política pública de educação profissional no Brasil, que compreende um importante esforço para a ramificação das escolas técnicas federais rumo ao interior do Brasil, com notável aporte de recursos orçamentários e de crescimento em número de servidores. No bojo da política e da ação estatal, pretende-se uma nova concepção de educação profissional em sua concepçáo original de criação da rede de educação profissional, inclusive com nova institucionalidade, os Institutos Federais, cuja marca própria identifica tal rede de modo direto em todos os estados da federação.

Podemos antecipadamente demarcar a importância dos institutos federais nas localidades em que sua presença se faz efetiva. Em que pese nos últimos anos políticas paliativas e focalizadas de formação profissional, como no caso do Programa Nacional de Acesso ao Ensino Técnico e Emprego (PRONATEC), a essência desse novo projeto institucional vem sendo preservada, baseada inclusive em um legado positivo que as instituições anteriores já possuíam quanto às ações de formação que desempenhavam, mesmo com as críticas pertinentes de necessidade de superação do modelo dual de educação em que se apoiavam historicamente. Em linhas gerais, pretende-se a superação dessas (con)tradiçôes e a projeção de uma nova identidade, inclusive com o aporte de novos programas educacionais, como o PROEJA, que antecede a criaçáo da concepção de rede federal de 2008, 
porém se apresentando como determinante para a superação paulatina do modus operandi das antigas escolas técnicas e agrotécnicas federais.

Convém determinar ainda que, nas novas instituiçóes surgidas na fase da expansão, um conjunto expressivo de novos servidores se evidencia como uma possibilidade de expressão dessa nova institucionalidade. No conjunto conceitual dos institutos federais, as concepçóes de currículo integrado, verticalização do ensino da educaçáo básica à pós-graduação e de estrutura organizacional anteposta ao modelo universitário brasileiro se colocam como mobilizadores de amplos debates nas próprias instituiçóes e nos segmentos acadêmicos quanto à observação e análise desse movimento. Na condição de estratégia do Estado, essa nova concepção da política nacional de educação profissional ainda não experimentou uma ampla avaliação.

Há distensóes, inclusive no caso do PRONATEC, que, como programa de governo, diverge fortemente da concepção original dos institutos federais, assemelhando-se ao modelo instrucional pautado pelo segmento empresarial por meio do Sistema "S" (SENAI, SENAC e outros) e causando estranhamento intra-rede. Nesse contexto, como avaliação pontual, o avanço dessa pesquisa possibilitou uma melhor compreensão do processo de mudanças anteriormente discutidas e, em um primeiro momento, possibilitou a participação dos atores sociais envolvidos, nem sempre incluídos no debate da concepção ou revisão da ação governamental no âmbito do ciclo das políticas públicas.

Assim, passa-se às fases previstas na metodologia de avaliação proposta por Saul (2006), articulando as etapas de Descrição da Realidade, Crítica da Realidade e Criação Coletiva com os instrumentos e metodologias determinados com o objetivo de subsidiar as análises necessárias deste processo investigativo aos seus autores.

\section{Descrição da Realidade}

\subsection{IFMA - Campus Açailândia: do lugar à caracterização institucional}

Em janeiro de 2008, por meio da Portaria MEC n. ${ }^{\circ}$ 156/2008, a então Unidade de Ensino Descentralizada de Açailândia (UNED), hoje Campus Açailândia, inicia oficialmente sua implantação, com a entrada efetiva em funcionamento em 31 de março do mesmo ano, e oferta inicial de 200 vagas para o ensino médio integrado ao curso técnico, sendo desse total 40 vagas para o PROEJA, cuja primeira formação oferecida era em Técnico em Alimentação Escolar.

Dados do Instituto de Pesquisa Econômica Aplicada (IPEA) indicam que entre os municípios médios, ou seja, aqueles em que a população gira entre 
100.000 e 500.000 habitantes, Açailândia apresenta-se como um fenômeno de crescimento em seus pouco mais de 30 anos de emancipação políticoadministrativa de Imperatriz-MA, ocorrida em 1981. O distrito de Açailândia surgiu nos idos da década de 1960, acompanhando o prolongamento do eixo rodoviário traçado para a rodovia Belém-Brasília na região sudoeste do Maranhão e dista 550 quilômetros da capital do estado. Seguiu trajetória de crescimento com o incremento da atividade agrícola, exploraçáo da atividade madeireira, e já na década de 1980 estava incluída no Projeto Grande Carajás como localidade que receberia a instalação do entroncamento ferroviário da Ferrovia Carajás e Norte-Sul, além de terminal de minérios da então estatal Cia. Vale do Rio Doce, atual Vale. De forma complementar, se instalaram empresas para o processamento primário de minério de ferro (guserias), dotando, assim, a regiáo de grande potencial econômico e com crescimento vertiginoso de sua população para os atuais 106 mil habitantes, composta de migrantes de várias partes do Brasil.

Nesse contexto, em que pese ter constado no âmbito do estado do Maranhão como um dos três maiores PIB per capita, pelos dados do Instituto Brasileiro de Geografia e Estatística - IBGE (2010), e estando incluída no contexto nacional com índice mediano de desenvolvimento humano municipal de 0,672 (segundo dados do Atlas do Desenvolvimento Humano no Brasil de 2013), apresenta problemas estruturais marcantes, além de demarcada desigualdade social e indicadores educacionais preocupantes. A título de exemplo, segundo dados do IBGE (2010), a taxa de analfabetismo consta em $17,02 \%$ para a população maior de 15 anos, enquanto a média nacional está em 9,37\%, ou seja, quase o dobro do indicador nacional, com involução discreta desse indicador, segundo dados também do IBGE (2016).

Açailândia apresenta uma economia bastante diversificada, porém com a prevalência de três importantes eixos:

a. Polo mineral e metalúrgico: polo industrial guseiro, processando em caráter primário e secundário o minério de ferro presente na região;

b. Polo de reflorestamento e de carvoejamento vegetal: implantação de significativas áreas de reflorestamento com eucalipto, para a produção de carvão e de ativos ambientais;

c. Produção de leite e derivados: apresenta uma das maiores bacias leiteiras do Maranhão, com projeção crescente de processamento do leite para produção de seus derivados. 
A avaliação do programa remete à implantação do curso técnico em Meio Ambiente (2011-2014), em que foi possível contar com os servidores e alunos que vivenciaram essa etapa, para efeito do desenvolvimento da pesquisa.

\subsection{Os planos de curso e documentos político-pedagógicos}

No cotidiano escolar, os documentos oficiais externam à comunidade de um modo geral o pretendido da ação do ente público e seus agentes, suas intençóes e objetivos. Nesse sentido, como estratégia interna de revisão de percurso quanto às ofertas de EJA, ao resgatar os planos de curso anteriormente elaborados para direcionamento da formação geral e técnica dos alunos da EJA no Campus Açailândia, pretendeu-se estabelecer as primeiras discussóes quanto aos referidos documentos e ao campo geral da concepção teórica dos Institutos Federais.

Como análise documental utilizou-se os projetos de curso do Técnico em Alimentação Escolar Integrado em Ensino Médio na modalidade EJA e do curso Técnico em Eletromecânica Integrado em Ensino Médio na modalidade EJA, ambos discutidos e finalizados no ano letivo de 2009. Os cursos foram ofertados à comunidade nos anos letivos de 2008 e 2009, respectivamente, com 40 vagas anuais e previsão de integralização em três anos letivos. O curso técnico em meio ambiente ainda está com projeto pedagógico em elaboração, apesar de três anos de funcionamento do curso.

Com relação à concepção, tais documentos indicam o consenso obtido para o delineamento da proposta de formaçáo desejada para os egressos dos referidos cursos e, nessa perspectiva, há um sensível salto qualitativo, pois enquanto o primeiro desenha uma formaçáo eminentemente técnica, o segundo interage como projeto na relação entre os saberes técnicos e científicos gerais, na intervenção da realidade local e na inserção do formando no mercado de trabalho.

Há de se entender que o arranjo institucional dos Institutos Federais, em que pese os documentos oficiais e os dados objetivos, frutos das discussóes e das contradições internas do espaço escolar, ainda estão em franca discussão e reelaboração. Isso também ocorre na elaboração dos projetos de curso, que refletem muito as dúvidas, as concepções de educação técnica e o conhecimento dos elaboradores sobre educação profissional e sua relação com a educação de jovens e adultos. Destaca-se, ainda, que na realidade da escola o planejado e o previsto podem se distanciar da prática cotidiana. Nesse momento, não há como discutir tal aspecto, que permeia a noção do currículo escolar e a prática dos professores em sala de aula, bem como o alinhamento/distanciamento do grupo docente e discente no percurso formativo. 
O planejamento para a revisão da oferta de EJA, no âmbito do PROEJA, considerou os seguintes aspectos por parte da comunidade de servidores:

a. Concepção geral dos planos de curso anteriores;

b. Resultados obtidos quanto à aprendizagem e índices de conclusão das primeiras turmas;

c. Redimensionamento da matriz curricular, mobilizando outros saberes e metodologias, adequando-se à modalidade de EJA;

d. Apropriação das bases legais e teóricas do PROEJA.

Mais adiante, a título de crítica da realidade, observa-se a possibilidade de verificar se as diretrizes iniciais e o planejamento feito para a oferta a partir do ano de 2011 do curso técnico em Meio Ambiente foram eficazes como retomada do percurso, considerando os indicadores anteriores e o avanço da implementação do PROEJA, especialmente no que diz respeito à oferta de vagas do novo curso, em 2011.

\subsection{Olhares sobre o PROEJA}

Os debates sobre educação profissional, e em especial a EJA no contexto dos Institutos Federais, apresentam-se de modo desafiante. A superação da dualidade histórica entre a educação propedêutica e a educação profissional, bem como a proposição de um currículo integrado, se coloca como ponto de partida para o avanço definitivo do pensar e fazer da educação tecnológica e profissional. Nesse amplo contexto, no bojo das discussóes no IFMA - Campus Açailândia, também perpassa o aprofundamento das questóes teóricas e metodológicas da pretensão de construção de propostas de ensino que aproximem os vários saberes para uma proposta unitária de formação, sem distinção da formação do técnico e do dirigente e na perspectiva da inter-relação entre educação e trabalho para uma formação ampla e justa.

Esse controverso tema apresenta-se de modo difuso nas falas da comunidade de servidores no Campus Açailândia.

Deveria ser feito um nivelamento desses alunos antes de começar de fato a dar aulas para eles. Como eles estáo chegando, se têm conhecimento. Porque além do ensino 
normal, eles vão ter ensino técnico. Às vezes nem a base do normal eles têm, ensino médio. Depois vão ter o técnico, chegam aqui e sentem essa dificuldade. Alguns conversam comigo, se sentem perdidos [...] agora a dificuldade é tirar esse projeto do papel e colocá-lo na prática, a partir da realidade que nós temos.

A priori, percebe-se uma grande dificuldade de dimensionamento por parte dos servidores sobre a pretensa formação integrada, ou mesmo currículo integrado, no âmbito da educação profissional, não apenas para o PROEJA. Muitas das discussóes perpassam apenas a sobreposição de conteúdos em detrimento de uma possível unidade teórica e conceitual em torno da concepção do próprio currículo.

Os professores, em especial, destacaram os problemas anteriores na formação escolar dos discentes que interferem no rendimento e andamento do trabalho, ou seja, o currículo idealizado enfrenta outras contingências pela heterogeneidade dos alunos admitidos na seleção anual. Eis um aspecto controverso, pois evidencia parcialmente a noçáo corrente nos outros turnos de ensino, especialmente o ensino médio diurno, de que o aluno deve vir pronto para acompanhar o ritmo da instituição.

Nas entrevistas com ambos os segmentos dos servidores, houve a possibilidade de discutir os argumentos dos participantes quanto ao nível de apropriação dos documentos e orientaçóes acerca do PROEJA.

As verbalizaçóes do primeiro nível de análise (descrição da realidade) indicaram que no nível interno ainda há pouco conhecimento acerca do Programa, e mesmo da política pública de EJA. Há o reconhecimento de que é insuficiente para o conjunto dos servidores os debates e leituras sobre o PROEJA, sua natureza e especificidade, marcos teóricos e conceituais, políticos e legais.

Acho que o grande pecado em lidar com o PROEJA hoje seria essa questão da formação do professor. Eu acho que o governo federal como um todo deveria incentivar capacitaçóes técnicas [...] especialização, discussóes para montagem de material, preparar o professor para lidar com esse público.

Isso se reflete no cotidiano escolar com os problemas relatados nos conselhos de classe sobre a dificuldade de prosseguimento do planejamento das disciplinas e da limitação dos alunos para o percurso formativo do ensino médio e técnico originalmente planejado. As discussóes são infindáveis, principalmente no tocante à sensibilização do grupo de servidores de que a ação docente na EJA deve ser diferente. 
Tem que ser um trabalho diferenciado. [...] eu sempre bato nessa tecla, o trabalho do PROEJA náo pode ser desenvolvido como você realiza a aula no integrado. Ele tem que ser trabalho diferenciado, a metodologia tem que ser diferenciada, avaliação diferenciada, lidar com o aluno tem que ser diferenciado...

Ao mesmo tempo em que há o reconhecimento das limitaçóes por parte da comunidade de servidores, relata-se a importância da oferta da educação de jovens e adultos, do apoio institucional e da formação dos professores para a melhoria das condiçóes de trabalho e do desenvolvimento das açóes pretendidas para a modalidade.

O segmento discente, público-alvo da política pública, observa de modo determinante o conjunto da instituição e as questóes que interferem no processo como um todo, não apenas a aprendizagem, mas também as condiçóes internas e externas que favorecem ou interferem na frequência e permanência dos alunos na instituição, ou seja, no âmbito do PROEJA. Organizando os dados a partir das categorias acesso e permanência, foi possível observar a remissão dos discentes aos problemas que mais lhes afetam quanto ao contexto ora explicitado, conforme observamos nos fragmentos a seguir:

Para mim, pode ser que alguém discorde, isso é um ponto negativo, até como na questâo do preconceito. Eu sei que todo mundo aqui é capaz.

O professor quer comparar a gente com os da manhá [...] Nós temos dificuldade. [...] A gente não tem que ter matérias [...] O mais importante seria tratamento diferenciado.

Dos que desistiram, era transporte, uns falaram que tinha relação com emprego, não batia horário, e outros questão de ciúmes, o marido não deixava. Esses três fatores.

$\mathrm{Na}$ perspectiva dos alunos, podemos perceber que a instituição enfrenta problemas e dilemas quanto a melhor forma de encaminhamento das questóes concernentes ao PROEJA. Quanto aos servidores também se observa a sensibilidade sobre as dificuldades dos alunos e enuncia-se que a instituição deve dar mais atenção e acompanhamento aos profissionais e aos alunos, conforme fragmentos anteriores.

Em análise aos argumentos expostos, destaca-se que há condições internas favoráveis, inicialmente, para o aprofundamento das discussóes sobre a EJA, 
o que seria uma possibilidade interessante para o desenho de uma proposta de ensino e de percurso formativo pautado na superação da dicotomia entre os saberes científicos/sistematizados e os saberes prévios dos discentes, bem como a inserção da categoria trabalho na ordem do dia quanto ao diálogo possível para uma formação educativa mais ampla e humana. Sobre esse aspecto, é representativo do contexto então apresentado e seu avanço a proposição de Ciavatta (2012, p. 92):

Continuamos a buscar o resgate do homem integral, a tornar os processos educacionais em açóes efetivas na formaçáo para o mundo do trabalho na visão ampliada [...] isto é, não a formação para a atividade laboral no sentido estrito, mas, também, as condiçôes de vida do trabalhador, com seus vínculos políticos e culturais.

Segundo Ciavatta (2012), na trajetória humana o conhecimento sempre foi uma reserva de poder das elites. Nesse sentido, a autora retoma as palavras de Gramsci, reiterando a crítica à escola interessada em detrimento a uma formação desinteressada e formativa, na perspectiva da escola unitária. A superação do modelo dualista ainda presente na formação e na prática dos professores, em especial nos atuantes na educação profissional, perpassa o processo de construçáo de novas bases teóricas sobre o que vem a ser uma formação para o trabalho ou para a intervenção no mundo do trabalho. Obviamente que a inserção do egresso no mercado de trabalho também é objeto de preocupação, afinal formação profissional sem inserção no mercado redunda no reconhecimento de que o papel formativo da instituiçáo foi estreito e meramente certificador, desvinculado da realidade da economia regional e seus arranjos produtivos.

Ainda no olhar dos profissionais, há especial reconhecimento da importância da oferta de cursos de formação profissional técnica na modalidade de EJA, pois resgatando as falas dos alunos, colhidas no cotidiano das aulas, e dos debates e intervençóes institucionais com os discentes desse segmento, estar no Instituto Federal e frequentando as aulas de um curso técnico representam de modo geral aos discentes a possibilidade de emprego ou sua manutençáo com salário digno. Aos mais jovens essa perspectiva se mostra muito mais interessante, ao passo que no olhar dos mais experientes a intenção é concluir o ensino médio como uma vitória pessoal. 


\section{Crítica da realidade}

\subsection{O olhar dos discentes}

O perfil dos alunos matriculados no PROEJA, via de regra, inclui um público que esteve há alguns anos fora do ambiente escolar, de jovens que buscam na formação técnica a inserção no mercado de trabalho dotado de qualificação profissional, bem como a promoção interna nos atuais ambientes de trabalho com a formação técnica. Acreditam ainda que o acesso ao curso técnico amplie as oportunidades de entrada no mercado de trabalho.

O documento base do PROEJA (BRASIL, 2007) define como funções do programa: reparar um público historicamente excluído da educação formal por uma série de razóes já discutidas, equalizar as oportunidades de trabalho mediante a formação humanística e técnica e qualificar cidadãos para uma justa inserção no campo produtivo da economia capitalista.

Para atender aos princípios do programa, a seleção dos alunos para o acesso às vagas do PROEJA inclui estratégias que visam identificar potencialmente $o$ público a ser atendido nessa modalidade da Educação Profissional e Tecnológica (EPT). Pontos como a experiência profissional, o perfil socioeconômico e os anos de afastamento da escola objetivam, se for possível em exames seletivos, tornar mais justo o certame de seleção de alunos e identificar o perfil de aluno desejado para o PROEJA, que em outras modalidades considera exclusivamente o mérito intelectual em uma prova objetiva de conhecimentos específicos com finalidade meramente classificatória.

De modo importante, estar estudando no IFMA representa uma importante conquista aos discentes. São valiosos os relatos quanto ao orgulho em estudar na escola em que seus próprios filhos estudam, revestindo-se de enorme significado simbólico.

É uma grande oportunidade. Hoje, o mercado de trabalho exige uma qualificaçáo melhor da pessoa. Eu acho muito bom aqui, o curso aqui. Tudo é maravilhoso, tudo de bom.

Há exatamente 20 anos que eu não entrava em uma sala de aula. E chegou um momento que eu tinha necessidade disso, estava me fazendo falta, pelo lado profissional... A gente fica muito tempo desinformado, 
você fica totalmente fora da sociedade. Você se sente excluído da sociedade.

Aqui tive um incentivo muito grande, me senti mais gente, mais pessoa, e vim para cá, tive mais oportunidades, foi mais fácil entrar aqui, ter feito o Programa Mulheres Mil. E estou aqui, quero ver se termino, estou grávida, mas não quero desistir, quero ir até o final.

Notadamente, as expectativas dos discentes quanto à instituição são as melhores possíveis. $\mathrm{O}$ agrupamento das falas dos discentes quanto às condiçóes de ensino e aprendizagem que a instituição oferece são também muito positivas, possibilitando identificar os pontos fracos da instituição e que podem ser melhorados.

A gente achava que era diferente o método de ensino aqui, os professores davam muitas atividades, as pessoas tinham dificuldades... O professor chegava aqui 'se não quiser, tchau e bençâo, tem mais o que fazer em casa ou na rua. As pessoas vinham do trabalho, dando duro, vinham para aula para ter um incentivo da escola. [...] Professor tem que ver isso, a questão do incentivo.

Material de estudo [...] Tem disciplina em que temos, outras náo temos. Temos que estar nos virando.

Há remissão na fala dos alunos quanto à importância da instituição e dos cursos oferecidos, assim como falas quanto ao cansaço em frequentar as aulas no turno noturno, e a professores sem paciência para lidar com suas dificuldades e fragilidades.

Outra coisa, o acarretamento das disciplinas, uma em cima da outra. Estamos aqui para estudar, não para enlouquecer. Ou seja, os professores deixam para passar seminários, como se nós fossemos pessoas que não têm nada para fazer durante o dia...

Nesse sentido, mesmo os professores reconhecendo suas fragilidades para o trabalho com a EJA, se coloca como desafio institucional o enfrentamento desse problema, que acreditamos provocar outras reaçóes, como a evasão e a infrequência dos discentes, em que pese a política de auxílio ao educando 
existente na instituição, com outorga de auxílio financeiro para despesas com transporte e material escolar e acompanhamento pedagógico, psicológico e do serviço social.

$\mathrm{O}$ aspecto da evasão dos discentes apresenta-se como um indicador muito grave quanto à efetividade do programa no âmbito da macro política pública de EJA, e para a própria instituição. Ao analisar apenas os números relativos à oferta do Curso Técnico em Meio Ambiente, a partir de 2011, podemos perceber bem esse aspecto:

Quadro 1: Fluxo de Matrículas. PROEJA 2011-2014 - Campus Açailândia

\begin{tabular}{|l|c|c|c|c|}
\hline Ano de Ingresso & Matriculados & Transferências & $\begin{array}{c}\text { Trancamento de } \\
\text { Matrícula }\end{array}$ & Evadidos \\
\hline 2011 & 40 & 1 & 0 & 20 \\
\hline 2012 & 40 & 0 & 3 & 22 \\
\hline 2013 & 40 & 0 & 0 & 15 \\
\hline 2014 & 39 & 0 & 0 & 00 \\
\hline
\end{tabular}

Fonte: Departamento de Registro e Controle Acadêmico - Campus Açailândia. 2014.

O conceito de evasão é muito controverso, em especial para a Educação de Jovens e Adultos. Porém, tal conceito se aplica tecnicamente diante dos órgãos de controle interno e externo, como o discente que náo atende espontaneamente aos prazos regulares de matrícula, de modo a não certificar a instituiçáo escolar de seu interesse ou desinteresse no prosseguimento dos estudos. Sob o aspecto técnico e quanto ao censo anual escolar, os números recebem tratamento específico, porém, considerando que a EJA precisa utilizar-se de mecanismos mais efetivos de garantia de acesso e permanência desse segmento, os fatores de evasão podem significar muito sobre o trabalho do conjunto da instituição, ou mesmo a busca pela efetividade da política pública. O debate não é meramente técnico.

Mas a questão premente a ser respondida é: o que causaria esse número alto de evadidos no PROEJA? Quais os meios e estratégias que a instituição possuiu para enfrentar esta realidade? Tais questóes estão na ordem do dia e foram abordadas pelos segmentos de entrevistados, considerando a crítica à realidade. Segundo os servidores:

Embora esses alunos tenham interesse em dar continuidade, ele não tem condiçóes materiais, embora a instituição tenha contribuição, ajuda através de um 
auxílio, mas muitas vezes fatores externos têm sido superiores para a permanência dele. O que considerar? Veja bem, é um ponto também fraco dos institutos, dentro da política de assistência: o aluno trabalhador não pode concorrer às bolsas ou auxílios.

Acho que a instituição devia passar isso para eles. O que vocês esperam da escola, a gente já sabe, agora, o que a instituição espera de vocês? Devia educar eles nesse sentido.

A instituição adota formato de seleção específico, conforme já apresentado. Essa seleção, segundo entendimento tanto dos professores quanto dos técnicos administrativos, fornece dados importantes sobre os futuros alunos, e tais informaçóes não são compartilhadas entre os profissionais como forma de antecipação das estratégias possíveis para o enfrentamento da evasão. Essa crítica é assimilada pelos profissionais, e despertou entre os participantes a percepção de que pouco ou nada se faz com esses dados, mesmo os que participam do processo, ou seja, tanto o setor pedagógico da instituição quanto o serviço social.

As consideraçóes dos discentes quanto ao baixo acompanhamento e quanto às dificuldades pontuais dos alunos, inclusive a necessidade de visitas domiciliares para os casos de infrequência, são uma constatação dos limites que a instituição possui no serviço de apoio ao educando. Podemos inferir que o reduzido quadro de servidores impóe dificuldades em fazer tal acompanhamento, diante da demanda de trabalho de todos os que atuam diretamente não só no PROEJA, mas nos outros turnos, turmas e segmentos de oferta educativa da instituição.

No conjunto das apreensóes dos alunos também consta que a instituição adote meios de proporcionar maior apoio aos professores, quer seja na organização do seu trabalho pedagógico, quer seja no aspecto pessoal. Para os discentes, professores com problemas pessoais não têm um bom rendimento. Eles observam que existem professores que não estão satisfeitos em estar na instituição porque estão distantes de seus familiares, considerando que um número representativo de servidores se desloca de outros municípios para seu local de trabalho semanalmente.

$\mathrm{Na}$ fala dos discentes esse aspecto interfere na condição de permanência do aluno, visto que as relaçóes interpessoais entre professores e alunos também podem determinar fatores de desmotivação e, por consequência, evasão dos discentes. 


\section{Criação Coletiva}

\subsection{Da tomada de consciência à busca de soluções: condições e contradições institucionais}

Em uma abordagem histórica, podemos afirmar que o acesso ou a negação da educação estabeleceu divisóes sociais que, com a crescente sofisticação dos meios de produção, aprofundaram ainda mais o abismo social existente entre as classes populares e a classe dirigente nas sociedades ditas capitalistas, pois, como regra, a posse do conhecimento determina a ocupação de postos no mercado de trabalho com as melhores remuneraçóes e o subemprego aos que foram alijados do processo educativo e de formação profissional.

As expectativas da comunidade escolar em relação ao PROEJA na instituição são muito positivas, e as propostas de encaminhamento dos problemas discutidos são vistas como de todos os atores sociais, sem que se perceba estratégia ou discurso que exima nenhum dos segmentos das responsabilidades na superação dos problemas.

Só que deveria ser feito um nivelamento desses alunos antes de começar de fato a dar aulas para eles. Como eles estão chegando, se têm conhecimento.

Podemos sugerir uma metodologia: temos 14 disciplinas, vamos estudar primeiro biologia... acabou? Entra matemática. Faz seminário. É uma boa, porque você faz só biologia, no final faz um seminário. Estudou só matemática... não vai ser dada a mesma quantidade de horas? É sequencial. Aprende melhor.

O que precisa ser feito, aí eu vou tentar colocar... Dois receios: não perder de vista quem é o público que estamos recebendo. Eu acho que a gente tem que potencializar a estrutura que temos para esse público alvo. Eu vou dar um exemplo, temos um projeto de curso, mas nós precisamos ter uma clareza maior desse projeto e o quanto que esse projeto pode favorecer e fortalecer o público-alvo que recebemos.

A ampliação da oferta de educação profissional e tecnológica na modalidade EJA deve vir acompanhada de correta formação pedagógica e de critérios de 
seleção que privilegiem tratamento diferenciado a quem recebeu tratamento desigual em sua trajetória escolar.

Ele tem que ser trabalho diferenciado quanto à metodologia, à avaliação, ao lidar com o aluno, ao horário de trabalho... deveria ser um horário diferenciado até para a entrada e saída deles aqui na escola.

Os mecanismos que propiciem a permanência devem ser aprimorados e ampliados, visto que a demanda reprimida ainda é significativa ante as vagas ofertadas na rede pública de EPT. Essa preocupação é perceptível nas falas dos entrevistados, e de modo positivo. Acreditamos haver condiçóes para estabelecer o debate acerca do PROEJA e as várias faces que a implantação da política pública estabelece como desafio. Entre a concepçáo, a implantação e sua continuidade, a avaliação do processo deve estar presente no ciclo das políticas públicas.

$\mathrm{O}$ percurso formativo apresenta-se como um dos pontos mais frágeis na concepção dos planos de curso e do próprio currículo. A preocupação com o emprego e a formação orientada para o exercício de uma função técnica específica, notadamente, é a maior preocupação e justificativa para a oferta dos cursos de EJA na percepção dos professores e técnicos.

Os debates sobre os princípios que norteiam a prática educativa ainda são incipientes, e a percepção da categoria trabalho como orientadora do processo formativo, mesmo que se apresente, é de forma reduzida ou pela simples formação operacional-técnica.

Para Kuenzer (2002), urge uma nova proposta de formação profissional na perspectiva de que:

É a posse do conhecimento que promoverá a passagem da aceitaçáo da autoridade para a autonomia, na perspectiva da autonomia intelectual e ética, permitindo que o trabalhador passe a ser partícipe, através de sua atividade, da criação de novas possibilidades de trabalho, no que diz respeito aos processos tecnológicos e às formas de organização. (KUENZER, 2002, p. 20).

O caráter propositivo dessa avaliação residiu ainda no cultivo da possibilidade de exercício de autonomia pelos atores sociais envolvidos, não apenas na discussão e avaliação do PROEJA, mas também em se perceberem como imersos em um contexto em que o crescente empoderamento quanto às questóes que lhes dizem respeito e que estão na pauta do dia das discussóes da instituição construirão 
a possibilidade de superação dos problemas. E mais: o senso de comunidade construído nas discussóes da política pública demonstraram o amadurecimento necessário para avançar autonomamente na busca de soluçóes e alternativas viáveis para a própria comunidade.

\section{Conclusões em nada definitivas: início de um novo debate?}

O desafio posto quanto à possibilidade de revisão de percurso sobre o PROEJA na rede federal são relevantes. Neste estudo, foi possível identificar o nível de autonomia crítica que a comunidade escolar exercitou. Isto favoreceu em muito a execução da metodologia de avaliação emancipadora, em que a participação qualitativa do coletivo escolar determinaria o sucesso da pesquisa.

Como desafio inicial desta pesquisa, a perspectiva de superação de incursóes empíricas anteriores favoreceu o desenvolvimento deste trabalho investigativo e o caráter de inovação ao vincular Avaliação Emancipadora com Análise de Conteúdo. Essa perspectiva permitiu uma análise por dentro, e não à margem da comunidade escolar ou com o peso individual de construir caminhos alternativos como um produto científico final. Outra possibilidade de inovação está no fato de ter despertado na comunidade escolar do IFMA - Campus Açailândia o protagonismo necessário para náo delegar a outros os encaminhamentos para alcançarem alternativas viáveis, pois a instituição por si e no exercício de poder simbólico do debate e das discussóes de sua comunidade abriu a possibilidade de autodeterminação de seus caminhos e opções.

Nos discentes foi determinante perceber, nos três momentos de entrevistas, a capacidade de externarem suas preocupaçóes e inquietaçóes e a possibilidade de intervirem de alguma forma no percurso diário de dificuldades que enfrentam, quer seja por limitaçóes e condições individuais, quer seja por condiçóes que a instituição e seus servidores insensivelmente não demonstram perceber.

Dos professores, ressaltamos a possibilidade de autonomamente superarem os problemas que lhes afetam na lida diária nas salas de EJA, pois o compromisso político do docente determina sua atuação em situaçôes análogas. Há anseio de querer transformar a realidade e o reconhecimento de que no Instituto Federal há uma possibilidade real de crescimento pessoal e profissional.

Como estratégias e proposiçóes levantadas no âmbito da pesquisa, cremos que cabe o destaque das proposiçóes dos atores sociais, inicialmente, a título de encaminhamentos dessas primeiras consideraçóes.

Quanto à evasão, na perspectiva dos discentes, notamos que os fatores externos exercem papel inicialmente mais determinante diante dos fatores internos. No 
município, há uma grande dificuldade quanto à oferta de transporte público, e isso tem interferido decisivamente no deslocamento dos discentes. Há de considerar, portanto, que o programa de auxílio transporte perde parte de sua eficácia. No âmbito interno, os alunos apontam e os servidores reconhecem que deve haver maior acompanhamento das açóes e dos alunos, de modo a evitar e monitorar as razóes das desistências ou infrequências, tentando agir nesse momento, e não após a impossibilidade de prosseguimento desse discente nos semestres letivos que se sucedem.

A formação pedagógica padece de maior efetividade, especialmente quanto ao conjunto de servidores que atuam no PROEJA, quer sejam professores, quer sejam técnicos administrativos, e aqui registramos nossa maior crítica. Percebemos que o nível de apropriação dos marcos legais e conceituais do programa é muito incipiente. Náo há teoria educacional que seja norteadora das açóes do conjunto dos servidores, mesmo considerando o nível interessante de entendimento acerca das especificidades na oferta da Educação de Jovens e Adultos à comunidade. Formamos para o mercado? E a formaçáo integral pretendida em superaçáo à instrução profissional? Notadamente, o isolamento dos segmentos componentes da comunidade escolar interfere na convergência de açóes para o enfrentamento dos problemas. Uma maior discussão, como a que foi possível no âmbito da pesquisa, poderia determinar maior efetividade da política pública, atacando de frente os baixos indicadores de certificaçáo escolar e os preocupantes números de evasão, fatores que ferem frontalmente a concepçáo do programa e seus mais caros princípios, possibilitando ir "[...] da sua aparência à essência das intençóes e das contradiçôes na sua formulação e implementação [...]", segundo Rêses e Silva (2017, p. 26).

Há uma grande necessidade de formação específica dos professores para a lida diária nas salas de EJA. Os próprios discentes ponderaram sobre as dificuldades na mediação dos saberes teóricos com os seus conhecimentos prévios. De modo geral, os professores partem das metodologias que são aplicadas aos adolescentes nas turmas do ensino médio integrado do turno diurno, tentando aproximar a prática idealizada de uma realidade divergente do contexto escolar, pois os jovens e adultos trabalhadores estão imersos em condiçóes sociais e escolares que não se assemelham às outras realidades dos outros segmentos escolares.

As tentativas de formação em serviço se perderam no tempo, nos idos de 2008, e desde então, em iniciativas pontuais são construídas alternativas para responder aos anseios de professores, técnicos e alunos. Cabe uma política institucional de capacitação para os profissionais que atuam na Educação de Jovens e Adultos, dotando-os não só de maiores e melhores possibilidades de intervenção no cotidiano da sala de aula, mas para perceberem nas especificidades 
dessa modalidade o relevante papel social que a política pública em si, mesmo na forma de um programa, exerce sobre as comunidades que são atendidas. Em Açailândia não seria diferente, pois está encravada em uma região de extremas desigualdades, em que a educação, a formação profissional e a formação humana devem ser mobilizadoras das transformaçóes necessárias diante do cenário real traduzido nos preocupantes indicadores sociais da região.

A pretensa e necessária integraçáo do currículo ainda é um vir a ser, especialmente no PROEJA. A possível articulação de saberes, ponto inicial quanto à concepção de integração da educação profissional e a educação básica, poderia tecer maiores aproximaçóes com as concepçóes teóricas que norteiam uma educaçâo do trabalho, como preceitua a pesquisadora Olgamir Carvalho (2003). Para ela, a relação precípua entre o binômio educação e trabalho estabelece as condiçóes necessárias para a concepção da escola unitária, emancipadora, e especialmente em superação ao modelo dual de educação, que reservou aos segmentos populares da sociedade brasileira a medida necessária de acesso à educaçáo para sua manutenção como classe subalterna. Essa é uma necessidade ancorada não só sob o aspecto de justiça social, mas também pela própria demanda de formaçáo de profissionais melhor qualificados, pois o desenvolvimento tecnológico requer trabalho e emprego de novo tipo, em total superaçáo aos paradigmas taylorista/ fordista, nos diz a autora. Esse é um grande desafio!

O PROEJA se apresenta enquanto proposta de integração da educação básica com a educação profissional como uma conquista "[...] advinda das lutas do Fórum Nacional em Defesa da Escola Pública pelo direito à educação e de resistência à perspectiva fragmentária, focalizada, compensatória e reducionista das ações de formação implementadas" (RÊSES, 2012, p. 108). De fato, o programa se apresenta como conquista e política necessária, mas a realidade da execução da política ainda pretende superar a visão dicotomizada e limitada de formação nos Institutos Federais.

\section{Referências}

BARDIN, Lawrence. Análise de conteúdo. Tradução Luís Antero Reto e Augusto Pinheiro. São Paulo: Edições 70, 2011.

BAUER, Martin W.; GASKELL, George (Org.). Pesquisa qualitativa com texto, imagem e som: um manual prático. 8. ed. Petrópolis: Vozes, 2010.

BRASIL. Decreto no $\mathbf{5 . 4 7 8 / 0 5}$. Institui, no âmbito das instituiçôes federais de educação tecnológica, o Programa de Integração da Educação Profissional 
ao Ensino Médio na Modalidade de Educação de Jovens e Adultos - PROEJA. Brasília, DF, 2005. Disponível em:<http://www.planalto.gov.br/ccivil_03/_ ato2004/2006/2005/Decreto/D5478.htm>. Acesso em: 30 de jan. 2015.

BRASIL. Decreto no 5.840/2006. Institui, no âmbito federal, o Programa Nacional de Integração da Educação Profissional com a Educação Básica na Modalidade de Educação de Jovens e Adultos - PROEJA, e dá outras providências. Brasília, DF, 2006. Disponível em: <http://www.planalto.gov.br/ccivil_03/_ ato2004-2006/2006/Decreto/D5840.htm>. Acesso em: 30 jan. 2015.

BRASIL. Ministério da Educação. Portaria n. 156/2008. Autoriza o funcionamento da Unidade de Ensino Descentralizada de Açailândia do CEFETMA. DOU - Edição n. 22/2008 de 31/01/2008. Disponível em: <http://www. pgp.ufv.br/wp-content/uploads/2012/06/Port_172-08_parte1.pdf>. Acesso: 30 jan. 2015.

BRASIL. Programa Nacional de Integraçáo da Educaçáo Profissional com a Educaçáo Básica na modalidade de Educaçáo de Jovens e Adultos - PROEJA. Documento Base. MEC. Brasília, DF, ago. 2007.

CARVALHO, Olgamir Francisco. Educaçáo e formação profissional - trabalho e tempo livre. Brasília, DF: Plano Editora, 2003.

CIAVATTA, Maria. Educação básica e Educação Profissional - descompassos e sintonia necessária. In: OLIVEIRA, Edna Castro de (Org.). EJA e Educaçáo Profissional: desafios da pesquisa e da formação no proeja. Brasília, DF: Líber Livro, 2012.

INSTITUTO BRASILEIRO DE GEOGRAFIA E ESTATÍSTICA (IBGE). Sinopse do Censo Demográfico de 2010. Disponível em: <https://censo2010. ibge.gov.br/sinopse/index.php?dados=P6\&uf=00>. Acesso em: 30 jan. 2015.

INSTITUTO BRASILEIRO DE GEOGRAFIA E ESTATÍSTICA (IBGE). Pesquisa Nacional por Amostra de Domicílios: síntese de indicadores. Rio de Janeiro: IBGE, 2016.

KUENZER, Acácia Z. Conhecimento e competências no trabalho e na escola. Boletim Técnico do Senac, Rio de Janeiro, v. 28, n. 2, maio/ago. 2002.

RÊSES, Erlando da Silva. Análise da inclusão do eixo trabalho nas políticas públicas de educação: avanços e desafios. In: CUNHA, Célio da; SOUSA, Jose Vieira de; SILVA, Maria Abadia da (Org.). Avaliaçáo de Políticas Públicas de Educaçáo. Brasília, DF: Faculdade de Educação / Universidade de Brasília, DF; Liber Livros, 2012. p. 93-113. 
RÊSES, Erlando da Silva; SILVA, Reinouds Lima. Interfaces da integração da educação de jovens e adultos com a educação profissional e o mundo do trabalho. In: RÊSES, Erlando da Silva; SALES, Marcia Castilho de; PEREIRA, Maria Luiza Pinho (Org.). Educaçáo de jovens e adultos Trabalhadores: políticas e experiências da integração à educação profissional. Campinas: Mercado das Letras, 2017.

SAUL, Ana Maria. Avaliaçáo emancipatória: desafios à teoria e à prática de avaliação e reformulação do currículo. 7. ed. São Paulo: Cortez, 2006.

SILVA, Reinouds Lima; RÊSES, Erlando da Silva. A educação de jovens e adultos no IFMA - Campus Açailândia: convergências, divergências e desafios sobre o processo de implantação do PROEJA no olhar da comunidade escolar. In: CONGRESSO NORTE E NORDESTE DE PESQUISA E INOVAÇÃO CONNEPI, 8., Salvador. Anais... Salvador: IFBA, 2013. 